American Journal of Pharmaceutical Education 2019; 83 (1) Article 6491.

\title{
RESEARCH
}

\section{Association Between Prerequisites and Academic Success at a Canadian University's Pharmacy Program}

\author{
Ed S. Krol, PhD, Roy Thomas Dobson, PhD, Kunmi Adesina, BSP \\ College of Pharmacy and Nutrition, University of Saskatchewan, Saskatoon, Saskatchewan, Canada \\ Submitted April 27, 2017; accepted October 25, 2017; published February 2019.
}

Objective. To identify pharmacy prerequisites associated with academic success in the current Bachelor of Science in Pharmacy (BSP) program and anticipated success in the planned Doctor of Pharmacy (PharmD) program at the University of Saskatchewan.

Methods. Statistical analysis was conducted on retrospective data of the grades of 1,236 pharmacy students admitted from 2002 to 2015. BSP success was calculated using a weighted average of all required courses within the BSP program. Anticipated success in the PharmD program was calculated from the BSP grades after excluding PharmD prerequisites currently part of the BSP. Models of BSP and PharmD prerequisites and demographic variables associated with pharmacy program success were constructed using stepwise and forced linear regression.

Results. For the current BSP program, modelling explained more than half of academic success in year 1. Explicable variance declined each year, explaining less than $20 \%$ in year 4 . After removing PharmD prerequisites from the program, the BSP prerequisites associated with success were the same as the first model but explained less of the variance in years 1 and 2. Using both BSP and the new PharmD prerequisites explained nearly three-quarters of the variance in year 1 for the remaining pharmacy courses. Explicable variance increased slightly in year 2, declined to approximately two-thirds in year 3 and just over one-half in year 4 .

Conclusion. Consistency of instructor and course content, along with instructional design and higherlevel learning, may explain these stronger associations for the PharmD prerequisites.

Keywords: pharmacy students, academic performance, prerequisites, knowledge application

\section{INTRODUCTION}

The first objective of this study was to identify pharmacy prerequisites associated with success in the professional pharmacy program at the University of Saskatchewan. For those prerequisites found to be associated with success in the program, the second objective was to determine whether courses associated with program success were qualitatively different in terms of how students were assessed, drew upon, or sought to develop higherorder learning skills.

The undergraduate pharmacy program in the College of Pharmacy and Nutrition at the University of Saskatchewan is currently transitioning from a Bachelor of Science in Pharmacy (BSP) to a Doctor of Pharmacy (PharmD), with the first cohort of the new program scheduled to start in fall 2017. Under the BSP program, students were

Corresponding Author: Ed S. Krol, Drug Discovery and Development Research Group, College of Pharmacy and Nutrition, University of Saskatchewan, 107 Wiggins Rd., Saskatoon, SK S7N 5E5, Canada. Tel: 306-966-2011. Fax: 306-966-6173. E-mail: ed.krol@usask.ca required to successfully complete 30 credit units (CU) (equivalent to one year, full-time undergraduate enrollment) of prerequisite courses in general biology, general chemistry, organic chemistry (level 1), English literature and composition, humanities (any two of psychology, sociology, philosophy or native studies) and two additional electives in humanities, social sciences or fine arts.

Because PharmD is the first professional pharmacy degree at this college, a substantial increase in the number of hours of practical training was deemed necessary. To accommodate this increase, the college elected to include only courses taught in the discipline of pharmacy during the PharmD program. As a result, seven courses taken within the BSP pharmacy program but delivered by units other than pharmacy were reclassified as pharmacy prerequisites: microbiology, nutrition, biomedical sciences (biochemistry), organic chemistry (level 2), physiology, mathematics, and statistics. Under the new PharmD program, total pharmacy prerequisites increased to $60 \mathrm{CUs}$, and the minimum time needed to complete all pharmacy prerequisites increased from one to two years. An additional benefit of this decision was to standardize 


\section{American Journal of Pharmaceutical Education 2019; 83 (1) Article 6491.}

the program for all students in terms of course workload. Previously, many of the "new" prerequisite courses could be taken prior to admission to the BSP; although, the majority of students completed these courses while enrolled in the BSP program. This resulted in a number of students carrying disproportionately fewer courses for the first two years of their program before experiencing full workload demands in the latter half of the program.

The general intention of prerequisite courses in pharmacy or any other professional program is to provide foundational knowledge prior to selection to a program. A 2008 survey of deans at pharmacy schools in the US indicated a general agreement on the importance of prepharmacy courses in the basic sciences for providing fundamental knowledge, ${ }^{1}$ and a white paper from 2009 suggested there may be potential benefits of a more standardized pre-pharmacy curricula in the US. ${ }^{2}$ Similar approaches are used in other pharmacy programs in Canada and across the US.

Performance in program prerequisites, in addition to other criteria, is often used when selecting students for admission to these programs. The use of grades as a measure of performance is arguably an imperfect measure of pharmacist professional skills. Over a decade ago, Houglum and colleagues assessed the ability of pharmacy prerequisites to predict academic success and failure when compared to cumulative GPA. ${ }^{3}$ Although various courses were seen as predictive of either success or failure, only organic chemistry was predictive of both success and failure. In addition to Houglum's findings, other criteria found to be predictive of student performance are advanced biology, a previous science baccalaureate, GPA, scores on the Pharmacy College Admission Test (PCAT), Multiple Mini Interview (MMI) and the California Critical Thinking Skills Test (CCTST). ${ }^{4-7}$

Several studies that focused specifically on predictors of failure observed relationships between PCAT, prepharmacy GPA, pre-pharmacy math and science GPA, first semester grade in an integrated science course, first and second semester GPA, and Multiple Mini Interviews (MMI) ${ }^{8-10}$ For the majority of courses, however, the ability to predict performance in the pharmacy program was not consistently evident. ${ }^{8-10}$

Given the general inability of academic performance in specific courses or in aggregate to predict academic success in a pharmacy program, we sought to identify qualitative factors of prerequisite courses associated with academic success in the pharmacy program. Rather than considering the type of course (ie, content), we were curious to what extent program success was a reflection of how the prerequisite course was assessed, or the extent that it drew upon or developed higher-order learning skills.

Courses used as prerequisites often differ in structure and learning objectives, and subsequently, the approaches and skills students employ to be successful in these courses also differ. Some courses contain large amounts of information that the student is required to memorize and present during an assessment. While it may not occur to the exclusion of knowledge synthesis and application, the capacity for memorization may be sufficient for success. For other courses, although memorization of information is still necessary, success is also predicated on a greater use of synthesis, integration and application of knowledge. For this study, therefore, once prerequisite courses were identified as significantly associated with program success, the objective was to identify the qualitative aspects of these prerequisite courses that might explain academic success in the pharmacy program.

\section{METHODS}

The study was approved by the Ethics Board at the University of Saskatchewan. The study population consisted of students admitted into the BSP Pharmacy program from 2002 to 2015. Admission and pharmacy program data were provided by the Office of the Registrar at the University of Saskatchewan. In addition to final grades in the professional pharmacy program, final grades were provided for all pharmacy prerequisite courses.

Prerequisites for the BSP included six CUs in each of the following subject areas: languages, biology, general chemistry, chemistry, and humanities. The average grade calculated for any six credits equivalent to English 110, 111, 112, 113 and 114, French 122 and 125, and literature 110, was used as the languages credit. For students with more than six credit units of these language courses, English 110 had first priority over other language courses, English courses were considered before French courses, and finally, French courses took precedence over literature. The grade obtained from either biology 110 or the average of biology 120 and 121 was used as the biology credit. General chemistry included grades obtained in either chemistry 112 or chemistry 114 . To calculate a grade in humanities, the average grade calculated for any six credits' equivalent of psychology, sociology philosophy or native studies courses was used.

Electives were excluded from this study due to the wide variation in courses students chose as their electives. For students who repeated any course, only the grade obtained in their first attempt was used in the study. Due to difficulty in consistently identifying courses taken at institutions other than the University of Saskatchewan, students who did not take all prerequisites at this 


\section{American Journal of Pharmaceutical Education 2019; 83 (1) Article 6491.}

university were excluded from analysis beyond basic demographics.

PharmD prerequisites used in the study consisted of non-pharmacy specific courses typically taken in the first two years of the BSP program. The courses included: Microbiology 224, Nutrition 120, Biomedical Sciences 230 (biochemistry), Organic Chemistry 255 (level 2), Physiology 208, Mathematics 125, and Statistics 246.

Researchers obtained demographic variables from the university's database which included gender, birth month and year, and the expected graduation year. Researchers calculated the admission age by subtracting the students' birth year plus four years from the expected graduation year.

BSP academic success was calculated using a weighted average of all required courses within the BSP program. The grade average for each year in the program was calculated based on the credit value of each course. A final weighted average was assigned for every student who had completed at least one year of the pharmacy program. Investigators calculated a proxy for success in the PharmD program from the BSP grades after excluding PharmD prerequisites currently part of the BSP. The weighted averages of the first two years of the BSP program were recalculated after excluding the courses that would become prerequisites of the PharmD program. None of the PharmD prerequisites are taken in the third and fourth year of the BSP program; therefore, there was no recalculation of these grade values.

Analysis was carried out using IBM SPSS Statistics for Windows, version 23 (IBM Corp., Armonk, NY). Analysis of the data included descriptive, correlation, and linear regression. Descriptive statistics were used to determine the characteristics and distribution of available data, and the variables extracted or created from the data. The correlation between yearly program success and the BSP and PharmD prerequisites were calculated. Models of factors contributing to academic success were constructed using stepwise and forced linear regression. The first set of models were created using stepwise linear regression analysis that observed the relationship between the dependent variable (yearly weighted average) and the independent (program prerequisites) and control (admission age and gender) variables. The second set of models used forced regression to examine the relationship between the yearly weighted averages and prerequisite courses with significant relationships, while ensuring the inclusion of gender and age as control variables. Statistical significance was set to an alpha level of .05.

Information on the qualitative characteristics of the prerequisite courses found to be associated with academic success in the pharmacy program was acquired from course syllabuses and the recollections of our undergraduate student researcher (graduated from the program June 2018). Where available to the authors, course instructors were contacted directly regarding pedagogical strategies and activities used in the course.

\section{RESULTS}

Of the 1,236 pharmacy students admitted to the program between 2002 and 2015, 915 (74\%) were female and $321(26 \%)$ male. The average age of students upon admission to the professional program between 2002 and 2015 was 21.7 years. The age of admission to the pharmacy program ranged from 18 to 44 , with nearly three-quarters (73.5) admitted between the ages of 19 and 21 (Figure 1). A total of 390 students $(31.6 \%)$ were excluded as a result of having at least one prerequisite completed at another university. Compared to the 846 students included in the final study analysis, the excluded students were slightly older on average (22.6 years vs 21.3 years), and a higher proportion of the excluded students were male (30.0\% vs. $24.1 \%)$.

Correlations between the BSP prerequisites and the weighted averages for each year of the BSP program were found to be very significant $(p<.01)$ (Table 1$)$. Correlations were highest in the first year of the pharmacy program and tended to decline in each subsequent year. Correlations also tended to be higher among science prerequisites in the early years of the BSP program.

Correlations between the PharmD prerequisites and the recalculated yearly program averages (BSP averages excluding courses now designated as prerequisites) were also found to be very significant $(p<.01)$. Correlations between the "old" BSP prerequisite and the "recalculated" yearly averages were slightly lower in years 1 and 2 compared to the actual BSP program yearly averages. The correlations between "new" PharmD prerequisites and the recalculated yearly averages, with the exception of mathematics, and statistics, and the fourth year average, were .50 or higher, and generally higher than the BSP prerequisites. The "new" PharmD prerequisite correlations declined over the four years of the program but generally to a lesser degree than for the BSP prerequisite correlations.

After controlling for admission age and gender, a limited number of the prerequisites were found to be significant in explaining the variance in the yearly averages of the BSP program (Table 2). Organic chemistry (level 1) was significant in all four years of the program, with biology significant in the first three years of the BSP program. The humanities average was significant in year 2 of the BSP program. In terms of explicable variance (adjusted R-squared), the model was able to account for just over half $(56 \%)$ of the observed variance. This 


\section{American Journal of Pharmaceutical Education 2019; 83 (1) Article 6491.}

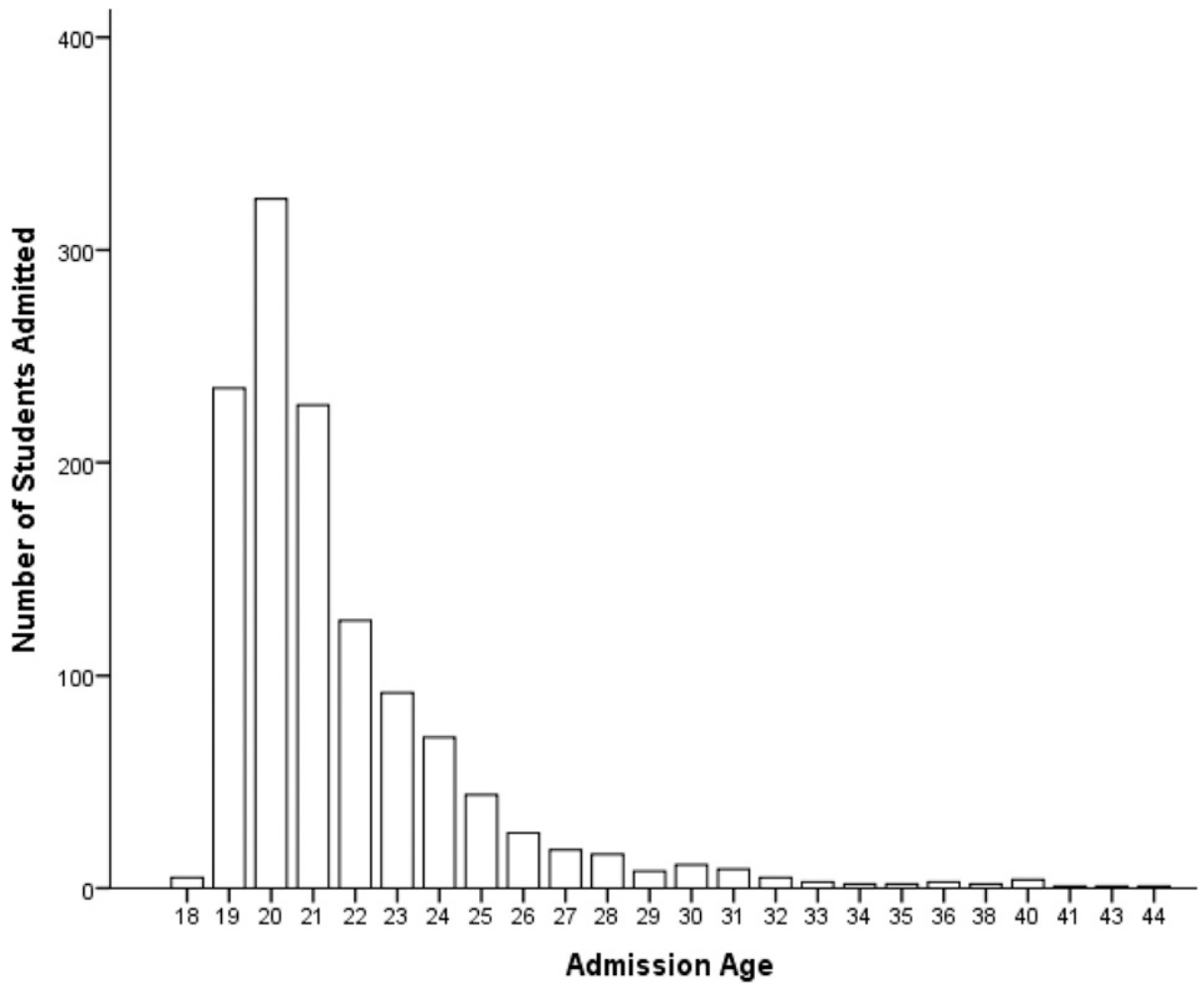

Figure 1. Age Distribution of Students Admitted to the BSP Program, 2002-2015.

declined to a third (33\%) in year 2 , to a quarter $(28 \%)$ in year 3 to $18 \%$ in year 4 .

The final model of the relationship between the yearly averages in the BSP program (excluding new
PharmD prerequisites) and BSP prerequisites is presented in Table 3. Similar to the previous model, organic chemistry (level 1) was significant in all four years, with biology significant in the first three years, and humanities

Table 1. Correlation Between Yearly Program Average and Pharmacy Program Prerequisites

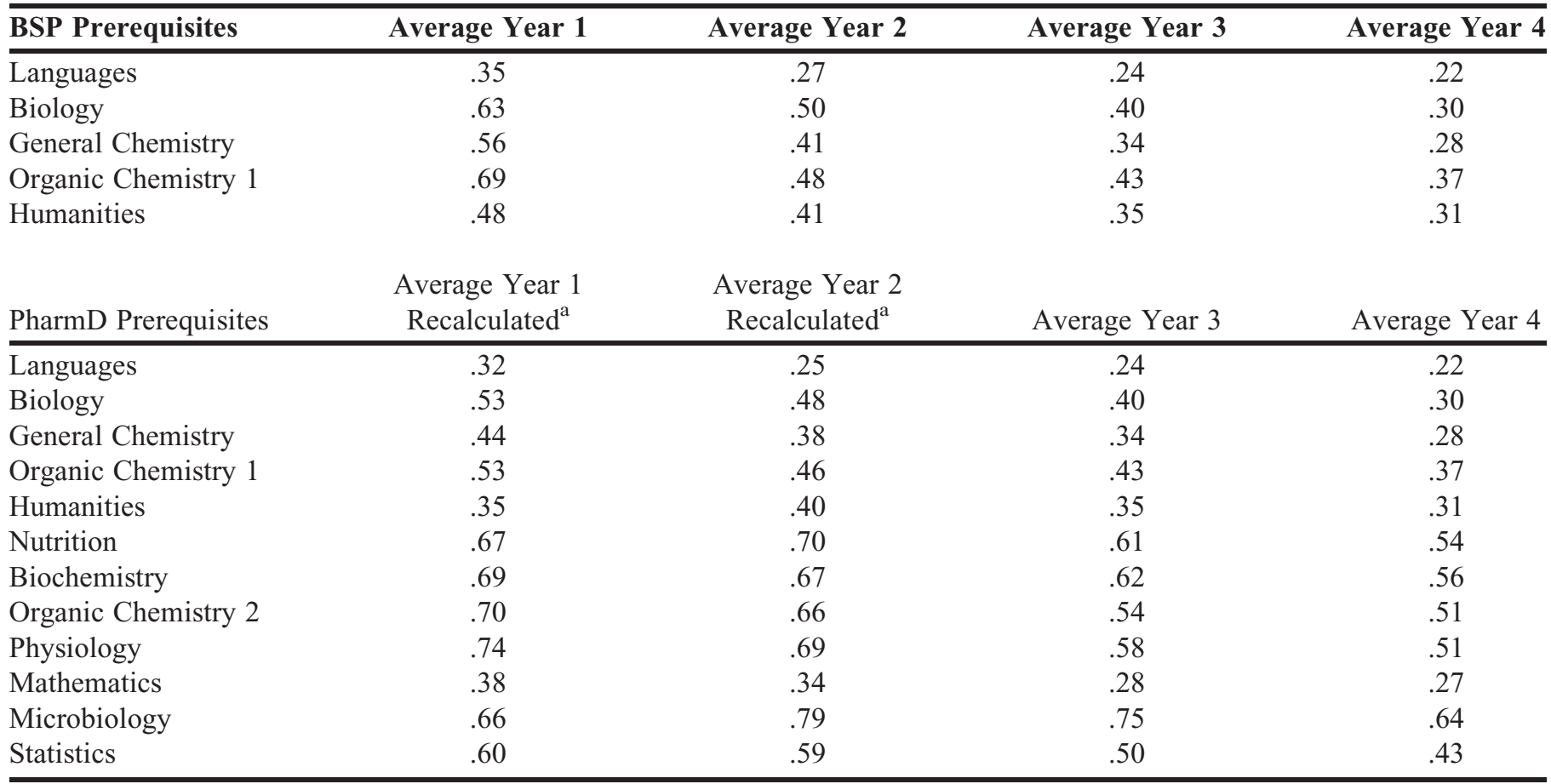

${ }^{a}$ Yearly program average after excluding courses designated as PharmD prerequisites 
American Journal of Pharmaceutical Education 2019; 83 (1) Article 6491.

Table 2. BSP Prerequisites Associated with Academic Success in the BSP Program

\begin{tabular}{|c|c|c|c|c|c|c|c|c|}
\hline \multirow[b]{2}{*}{ Variables } & \multicolumn{2}{|c|}{$\begin{array}{c}\text { Unstandardized } \\
\text { Coefficients }\end{array}$} & \multirow{2}{*}{$\begin{array}{c}\begin{array}{c}\text { Standardized } \\
\text { Coefficient }\end{array} \\
\text { Beta }\end{array}$} & \multirow[b]{2}{*}{$t$} & \multirow[b]{2}{*}{ Sig. } & \multirow[b]{2}{*}{$R$ value } & \multirow[b]{2}{*}{$\mathbf{R}^{2}$} & \multirow{2}{*}{$\begin{array}{c}\text { Adjusted } \\
\mathbf{R}^{\mathbf{2}}\end{array}$} \\
\hline & Beta & Standard Error & & & & & & \\
\hline Year 1 & & & & & & & & \\
\hline (Constant) & 24.67 & 3.20 & - & 7.70 & .00 & & & \\
\hline Organic Chem. 1 & 0.37 & 0.03 & 0.49 & 12.83 & .00 & & & \\
\hline Biology & 0.33 & 0.04 & 0.34 & 8.80 & .00 & & & \\
\hline Admission Age & -0.16 & 0.08 & -0.07 & -2.10 & .04 & & & \\
\hline Gender & 1.34 & 0.54 & 0.08 & 2.46 & .01 & .75 & .56 & .56 \\
\hline \multicolumn{9}{|l|}{ Year 2} \\
\hline (Constant) & 36.81 & 4.41 & - & 8.34 & .00 & & & \\
\hline Organic Chem. 1 & 0.19 & 0.04 & 0.28 & 5.13 & .00 & & & \\
\hline Biology & 0.23 & 0.05 & 0.26 & 4.36 & .00 & & & \\
\hline Humanities & 0.10 & 0.05 & 0.12 & 2.16 & .03 & & & \\
\hline Admission Age & -0.11 & 0.12 & -0.04 & -0.91 & .36 & & & \\
\hline Gender & 2.57 & 0.67 & 0.16 & 3.81 & .00 & .58 & .34 & .33 \\
\hline \multicolumn{9}{|l|}{ Year 3} \\
\hline (Constant) & 49.07 & 3.88 & - & 12.66 & .00 & & & \\
\hline Organic Chem. 1 & 0.17 & 0.04 & 0.27 & 4.57 & .00 & & & \\
\hline Biology & 0.20 & 0.05 & 0.25 & 4.14 & .00 & & & \\
\hline Admission Age & -0.23 & 0.10 & -0.11 & -2.24 & .00 & & & \\
\hline Gender & 3.15 & 0.67 & 0.22 & 4.68 & .00 & .53 & .28 & .28 \\
\hline \multicolumn{9}{|l|}{ Year 4} \\
\hline (Constant) & 62.69 & 3.88 & - & 16.14 & .00 & & & \\
\hline Organic Chem. 1 & 0.22 & 0.03 & 0.37 & 7.03 & .00 & & & \\
\hline Admission Age & -0.33 & 0.13 & -0.14 & -2.65 & .01 & & & \\
\hline Gender & 2.38 & 0.71 & 0.18 & 3.33 & .00 & .44 & .19 & .18 \\
\hline
\end{tabular}

significant in year 2. In terms of explicable variance (adjusted $\mathrm{R}^{2}$ ); however, explicable variance declined in the first two years of the program, with the model only able to account for just over one-third (36\%) of the variance in year 1 , and $30 \%$ in year 2. As no new prerequisites came from years 3 and 4 of the BSP program, explicable variance remained the same for the final two years of the BSP program.

The relationships between the PharmD prerequisites and the recalculated yearly averages of the pharmacy program are presented in Table 4 . The factors that best explained the variance in yearly pharmacy averages were generally those described as "new" PharmD prerequisites (courses within the current BSP program). Nutrition was a contributor to all years as an explanatory variable. Microbiology and statistics were each significant in three of four years. Biochemistry (years 3 and 4) and Organic Chemistry 255 (years 1 and 2) were contributors to two of the four years. Nutrition, along with organic chemistry (level 2), statistics, physiology, admission age, and gender accounted for nearly three-quarters $(73 \%)$ of the variance observed in year 1 averages. Explicable variance increased to $78 \%$ in year 2 with microbiology, nutrition, statistics and gender identified as significant variables. In year 3 , explicable variance fell to just under $70 \%\left(\mathrm{R}^{2}=0.68\right)$ with microbiology, nutrition, and statistics, along with biochemistry, age and gender found to be significant. Just over half of the variance (52\%) was explained by the model in year 4, with microbiology, nutrition, biochemistry and biology found to be significant.

\section{DISCUSSION}

Seventy-four percent of the students admitted into the pharmacy program were female, a pattern similar to other pharmacy schools across North America. ${ }^{11}$ Students' average age at admission was 22 years and this number was not unexpected since students admitted to this program are not required to complete a degree to be eligible for admission. The high percentage of students with all prerequisites completed at the University of Saskatchewan (68.4\%) reflects the position of the university as the principal academic institution in the province of Saskatchewan. This high percent is also a reflection of several health care training programs located at the university. 


\section{American Journal of Pharmaceutical Education 2019; 83 (1) Article 6491.}

Table 3. BSP Prerequisites Associated with Academic Success in the BSP Program (excluding courses designated PharmD prerequisites)

\begin{tabular}{|c|c|c|c|c|c|c|c|c|}
\hline \multirow[b]{2}{*}{ Variables } & \multicolumn{2}{|c|}{$\begin{array}{l}\text { Unstandardized } \\
\text { Coefficients }\end{array}$} & \multirow{2}{*}{$\begin{array}{c}\begin{array}{c}\text { Standardized } \\
\text { Coefficient }\end{array} \\
\text { Beta }\end{array}$} & \multirow[b]{2}{*}{$t$} & \multirow[b]{2}{*}{ Sig. } & \multirow[b]{2}{*}{$R$ value } & \multirow[b]{2}{*}{$\mathbf{R}^{2}$} & \multirow{2}{*}{$\begin{array}{c}\text { Adjusted } \\
\mathbf{R}^{\mathbf{2}}\end{array}$} \\
\hline & Beta & Standard Error & & & & & & \\
\hline $\begin{array}{l}\text { Year } 1 \\
\text { (Constant) }\end{array}$ & 35.04 & 3.46 & - & 10.13 & .00 & & & \\
\hline Organic Chem. 1 & 0.23 & 0.03 & 0.34 & 7.43 & .00 & & & \\
\hline Biology & 0.29 & 0.04 & 0.33 & 7.24 & .00 & & & \\
\hline Admission Age & 0.00 & 0.08 & 0.00 & 0.05 & .96 & & & \\
\hline Gender & 1.87 & 0.59 & 0.12 & 3.18 & .00 & .60 & .37 & .36 \\
\hline \multicolumn{9}{|l|}{ Year 2} \\
\hline (Constant) & 32.80 & 4.72 & - & 6.94 & .00 & & & \\
\hline Organic Chem. 1 & 0.19 & 0.04 & 0.27 & 4.93 & .00 & & & \\
\hline Biology & 0.22 & 0.06 & 0.23 & 3.86 & .00 & & & \\
\hline Humanities & 0.12 & 0.05 & 0.12 & 2.28 & .02 & & & \\
\hline Admission Age & -0.01 & 0.12 & -0.00 & -0.11 & .91 & & & \\
\hline Gender & 2.80 & 0.72 & 0.17 & 3.88 & .00 & .56 & .31 & .30 \\
\hline \multicolumn{9}{|l|}{ Year 3} \\
\hline (Constant) & 49.07 & 3.88 & - & 12.66 & .00 & & & \\
\hline Organic Chem. 1 & 0.17 & 0.04 & 0.27 & 4.57 & .00 & & & \\
\hline Biology & 0.20 & 0.05 & 0.25 & 4.14 & .00 & & & \\
\hline Admission Age & -0.23 & 0.10 & -0.11 & -2.24 & .00 & & & \\
\hline Gender & 3.15 & 0.67 & 0.22 & 4.68 & .00 & .53 & .28 & .28 \\
\hline \multicolumn{9}{|l|}{ Year 4} \\
\hline (Constant) & 62.69 & 3.88 & - & 16.14 & .00 & & & \\
\hline Organic Chem. 1 & 0.22 & 0.03 & 0.37 & 7.03 & .00 & & & \\
\hline Admission Age & -0.33 & 0.13 & -0.14 & -2.65 & .01 & & & \\
\hline Gender & 2.38 & 0.71 & 0.18 & 3.33 & .00 & .44 & .19 & .18 \\
\hline
\end{tabular}

Based on the findings of earlier research examining predictors of academic performance, we anticipated that the strongest correlation between prerequisites and the weighted averages would be seen in year 1 of the pharmacy program, progressively becoming weaker as students advanced through the program. ${ }^{4}$ Overall, this trend was observed for both the BSP and PharmD prerequisites, although the PharmD prerequisites displayed much stronger relationships with student averages across the four years of the pharmacy program.

Similar to other studies, the BSP prerequisites that explained variance were primarily organic chemistry and biology. ${ }^{3,4}$ These courses explained $56 \%$ of the variance in the year 1 averages with the explained variance falling to $18 \%$ in year 4. Courses previously part of the BSP that are now prerequisites for the PharmD were better able to explain variance in the weighted averages and accounted for the majority of the explained variance in student weighted averages in year 4.

Performance in nutrition was associated with academic success in pharmacy courses (recalculated) in all four years of the program; therefore, we sought to better understand what differentiated this course from others. For Nutrition, approximately $40 \%$ of the course assessment requires students to apply knowledge learned throughout the course, ie, forming complex relationships from multiple concepts. Students must apply several important aspects of higher-level learning, notably knowledge organization and development of mastery, in order to succeed in applying knowledge. ${ }^{12}$

A consistency of instruction is seen with Nutrition in that the course has been taught by the same instructor for over 10 years. During this time, the instructor has provided opportunities for formative feedback throughout the course, including online quizzes and discussion groups. Student discussion groups, although a more recent addition to the course, are noteworthy as they provide an opportunity for students to practice synthesizing and applying knowledge. According to Ambrose and colleagues in How Learning Works. Seven Research-based Principles for Smart Teaching, providing cognitive supports early, such as scaffolding, is important to building the skills of knowledge synthesis 


\section{American Journal of Pharmaceutical Education 2019; 83 (1) Article 6491.}

Table 4. PharmD Prerequisites Associated with Academic Success in the BSP Program (excluding courses designated PharmD prerequisites)

\begin{tabular}{|c|c|c|c|c|c|c|c|c|}
\hline \multirow[b]{2}{*}{ Variables } & \multicolumn{2}{|c|}{$\begin{array}{l}\text { Unstandardized } \\
\text { Coefficients }\end{array}$} & \multirow{2}{*}{$\begin{array}{c}\begin{array}{c}\text { Standardized } \\
\text { Coefficient }\end{array} \\
\text { Beta }\end{array}$} & \multirow[b]{2}{*}{$t$} & \multirow[b]{2}{*}{ Sig. } & \multirow[b]{2}{*}{$R$ value } & \multirow[b]{2}{*}{$\mathbf{R}^{2}$} & \multirow{2}{*}{$\begin{array}{c}\text { Adjusted } \\
\mathbf{R}^{\mathbf{2}}\end{array}$} \\
\hline & Beta & Standard Error & & & & & & \\
\hline $\begin{array}{l}\text { Year } 1 \\
\text { (Constant) }\end{array}$ & 13.98 & 2.57 & - & 5.43 & .00 & & & \\
\hline Organ. Chem. 2 & 0.18 & 0.02 & 0.32 & 8.24 & .00 & & & \\
\hline Nutrition & 0.23 & 0.03 & 0.27 & 7.93 & .00 & & & \\
\hline Physiology & 0.18 & 0.03 & 0.25 & 6.32 & .00 & & & \\
\hline Statistics & 0.16 & 0.03 & 0.18 & 5.99 & .00 & & & \\
\hline Admission Age & 0.14 & 0.06 & 0.06 & 2.23 & .03 & & & \\
\hline Gender & 1.57 & 0.40 & 0.10 & 3.96 & .00 & .86 & .74 & .73 \\
\hline \multicolumn{9}{|l|}{ Year 2} \\
\hline (Constant) & 1.67 & 2.78 & - & 0.60 & .55 & & & \\
\hline Microbiology & 0.42 & 0.03 & 0.44 & 13.51 & .00 & & & \\
\hline Organ. Chem. 2 & 0.16 & 0.02 & 0.27 & 8.12 & .00 & & & \\
\hline Nutrition & 0.16 & 0.03 & 0.16 & 4.92 & .00 & & & \\
\hline Statistics & 0.15 & 0.03 & 0.16 & 5.35 & .00 & & & \\
\hline Admission Age & 0.00 & 0.06 & 0.00 & 0.03 & .98 & & & \\
\hline Gender & 1.64 & 0.42 & 0.09 & 3.92 & .00 & .89 & .79 & .78 \\
\hline \multicolumn{9}{|l|}{ Year 3} \\
\hline (Constant) & 19.13 & 2.81 & - & 6.82 & .00 & & & \\
\hline Microbiology & 0.36 & 0.03 & 0.45 & 10.79 & .00 & & & \\
\hline Biochemistry & 0.11 & 0.02 & 0.20 & 4.73 & .00 & & & \\
\hline Nutrition & 0.12 & 0.03 & 0.15 & 3.43 & .00 & & & \\
\hline Statistics & 0.12 & 0.03 & 0.14 & 4.10 & .00 & & & \\
\hline Admission Age & -0.14 & 0.06 & -0.06 & -2.16 & .03 & & & \\
\hline Gender & 1.47 & 0.44 & 0.10 & 3.38 & .00 & .83 & .69 & .68 \\
\hline \multicolumn{9}{|l|}{ Year 4} \\
\hline (Constant) & 33.08 & 4.07 & - & 8.12 & .00 & & & \\
\hline Microbiology & 0.36 & 0.05 & 0.47 & 7.19 & .00 & & & \\
\hline Nutrition & 0.18 & 0.05 & 0.23 & 3.51 & .00 & & & \\
\hline Biochemistry & 0.09 & 0.04 & 0.17 & 2.71 & .01 & & & \\
\hline Biology & -0.10 & 0.04 & -0.13 & -2.29 & .02 & & & \\
\hline Admission Age & -0.16 & 0.10 & -0.07 & -1.61 & .11 & & & \\
\hline Gender & 0.82 & 0.63 & 0.06 & 1.31 & .19 & .73 & .53 & .52 \\
\hline
\end{tabular}

and application. ${ }^{12}$ The instructor designed feedback from the online quizzes with scaffolding in mind. Synthesis and application of knowledge requires the learner to use prior knowledge combined with declarative knowledge (facts) and procedural knowledge (knowing when and how to apply). ${ }^{13}$ An important component of developing these skills is filtering inappropriate or inaccurate prior knowledge, a role that the discussion groups addressed. ${ }^{14}$ A limitation to this interpretation was our inability to determine which students took advantage of the discussion groups.

Reflection on the roles of a pharmacist suggests that the ability to organize efficiently complex interconnected knowledge and develop mastery of skills, including the transfer of component skills to complete complex cognitive tasks, would be beneficial. We hypothesize that the students who have developed or can readily implement these skills in the required nutrition course may be more likely to transfer these skills to tasks demanded of them in the pharmacy curriculum.

A prerequisite course found to have a significant association with program success in three out of four years of the program was microbiology. Microbiology contains content that is crucial for learning later in the BSP. The microbiology course at this university uses a comprehensive final laboratory examination as an assessment tool rather than weekly laboratory reports found in 


\section{American Journal of Pharmaceutical Education 2019; 83 (1) Article 6491.}

the majority of courses with a laboratory component. The laboratory examination is designed for learners to apply the knowledge they have gained throughout the laboratory classes. For example, students are asked to assess which laboratory method should be used to analyze a data sample, rather than provide a description for a specific laboratory protocol. As part of the laboratory instruction the relevance of the laboratory technique being studied, including how and why it would be used, is emphasized. The use of a final laboratory examination may differentiate students in ways that weekly laboratory reports may not perhaps because the laboratory examination requires a level of skill mastery rather than competency for a single component in a report.

The use of multiple formative assessments has been shown to be optimal for development of knowledge application and mastery. ${ }^{15}$ While the students in the microbiology course do not receive formal written formative assessments for the labs, the labs are designed to provide informal feedback. Even this level of formative feedback may have contributed to improved mastery of knowledge. In addition, students for whom skill mastery was more developed may have been better able to apply these skills in the summative laboratory examination. A single laboratory examination (and the grade associated with it), therefore, may be a more accurate reflection of a student's ability to apply the knowledge that they have learned throughout the course. In other words, the grade stratification may, at least partially, reflect a student's ability to incorporate and apply interconnected knowledge.

A previous study into student perceptions of the relevance of organic chemistry in a pharmacy program suggested relevance to pharmaceutical/medicinal chemistry aspects but not for professional success. ${ }^{16}$ In our study, both levels 1 and 2 organic chemistry were prominent variables in the explanatory models (Tables 2-4). As with other notable variables, one characteristic of the organic chemistry courses is the requirement to form complex interrelationships between abstract concepts. Organic chemistry instructors at this university discourage memorization of chemical reactions; instead, they stress an understanding of fundamental concepts and application of these concepts. For example, the intrinsic reactivity of molecules (such as what portion of a molecule is an electrophile, what portion of a molecule is a nucleophile) is stressed instead of "molecule A reacts like this" to direct students' learning toward knowledge synthesis. Instructors use multiple presentation methods to deliver the course material, and they use both lecture time and tutorials to provide an opportunity for students to practice mastery of more complex problems and, importantly, to receive formative feedback on these skills (especially the tutorials). Furthermore, faculty design methods of assessment specifically to test understanding and application rather than memorization where the students must be able to apply their knowledge to new situations, such as the synthesis of a molecule they have never seen before. Together, the methods of assessment used in these courses provide possible insight into their predictive ability as they assess skills that appear critical for pharmacy students to develop through their program of studies.

Of the two remaining courses that could explain student performance (statistics and biochemistry), the method of assessment in statistics supports our suggestion of the importance of knowledge application. Students are allowed to bring documents containing relevant formulas to their examinations with assessment testing the ability to correctly apply the formulas to statistical problems. Conversely the biochemistry course relied heavily on memorization. Although the ability to organize related material for more efficient memorization may contribute to success in the biochemistry course, it is less clear that the specific skillset of knowledge application is necessary.

Although the knowledge obtained in these and other prerequisite courses is valuable for inherent foundational knowledge, we propose that selected courses may support the development of these higher level cognitive skills; to what extent students took advantage of these supports is unknown. We may have identified which students have developed the skills for knowledge mastery and application as a result of the methods of assessment in certain prerequisite courses; however, we cannot determine whether these skills were developed in these prerequisite courses, prior to these courses, or if some students were able to take better advantage of the supports in these courses for skill development.

An important limitation of using correlation analysis of grades for courses taught over a span of years is the impact of different instructors and their teaching and assessment approaches. To the best of our knowledge, the prerequisite courses were delivered as traditional didactic lectures; although, we anticipate that the flipped classrooms, in which there is a greater emphasis on self-directed learning because the students monitor and control their own learning, might better facilitate students' growth of knowledge application. ${ }^{17}$ It is noteworthy that the course with the strongest association (nutrition) has been taught by the same instructor for over 10 years and the instructor is well recognized for course and assessment design, including a university-level teaching award. That nutrition has the strongest association with student performance may partly be the result of the consistency in the delivery and assessment of this course over the years of this study. 


\section{American Journal of Pharmaceutical Education 2019; 83 (1) Article 6491.}

An additional limitation to this study was the inability to more fully analyze data from transfer students. Because of the variety of ways certain courses are named and graded in different universities, the courses taken in other institutions were excluded in this study. This affected the study population in that those excluded were more often male and slightly older than the study cohort.

The pharmacy courses used to test for an association with PharmD prerequisites are somewhat different from the courses proposed for the PharmD program starting in 2017. While overall content is generally comparable, how and when students will engage with the PharmD content is expected to be different; thereby, this limits the generalizability of the study-findings to the new program.

While some students in the BSP program were able to take some year 1 and year 2 courses now defined as PharmD prerequisites prior to admission in the program, most BSP students took these concurrently with pharmacy-specific courses. The high association between the PharmD prerequisite courses and pharmacy courses, therefore, may be due to similarity of grades for a student across courses in any given year. That being said, the courses offered by units other than pharmacy show evidence that they may be predictive of student performance in pharmacy-specific courses.

It is our assertion that development of these higherlevel learning attributes may be a critical component for pharmacy students to realize optimal learning behaviors and application of their knowledge. Therefore, we suggest that instructors should consider implementing directed practice exercises coupled with well-timed and task appropriate feedback to support the development of higher level skills, especially mastery and application of knowledge.

\section{CONCLUSION}

Numerous pharmacy programs have investigated the ability of various admissions criteria to predict future performance in their respective programs. Although GPA is typically used to assess performance, other indicators such as the North American Pharmacy Licensing examination (NAPLEX), dismissal from the program and delayed progression have also been used..$^{3-9,18-22}$ For this study, we retrospectively assessed the ability of BSP and PharmD prerequisite courses to explain student academic performance in the pharmacy program at the University of Saskatchewan. Based on the types of courses identified, we suggest that these courses may be important in that they require the development of higherlevel learning skills such as knowledge organization, skill mastery and knowledge synthesis and application, all of which are skills that might determine success in the pharmacy program.
Finally, it is not our goal to use this information to alter admission criteria or identify a specific course or courses to use as criteria for admission. Rather we sought to identify aspects of a course (or courses) that might provide insight into qualitative characteristics of the courses that may explain student success.

\section{ACKNOWLEDGMENTS}

Thank you to Ms. Melanie Rozwadowski, and Drs. David Palmer and Harry Deneer for insightful discussions on instructional design at the University of Saskatchewan.

\section{REFERENCES}

1. Broedel-Zaugg K, Buring SM, Shankar N, et al. Academic pharmacy administrators' perceptions of core requirements for entry into professional pharmacy programs. Am J Pharm Educ. 2008;72(3): Article 52.

2. Boyce EG, Lawson LA. Preprofessional curriculum in preparation for doctor of pharmacy educational programs. Am J Pharm Educ. 2009;73(8):Article 155.

3. Houglum JE, Aparasu RR, Delfinis TM. Predictors of academic success and failure in a pharmacy professional program. Am J Pharm Educ. 2005;69(3):Article 43.

4. McCall KL, Allen DD, Fike DS. Predictors of academic success in a doctor of pharmacy program. Am J Pharm Educ 2006;70(5): Article 106.

5. Unni EJ, Zhang J, Radhakrishnan R, et al. Predictors of academic performance of pharmacy students based on admission criteria in a 3-year pharmacy program. Curr Pharm Teach Learn. 2011;3(3): 192-198.

6. Tejada FR, Parmar JR, Purnell M, Lang LA. Admissions criteria as predictors of academic performance in a three-year pharmacy program at a historically black institution. Am J Pharm Educ. 2016;80(1):Article 6.

7. McCall KL, MacLaughlin EJ, Fike DS, Ruiz B. Preadmission predictors of PharmD graduates' performance on the NAPLEX. Am J Pharm Educ. 2007;71(1):Article 5.

8. Heldenbrand SD, Flowers SK, Bordelon BJ, et al. Multiple miniinterview performance predicts academic difficulty in the PharmD curriculum. Am J Pharm Educ. 2016;80(2):Article 27.

9. Hardinger KL, Schauner S, Graham MR, Garavalia L. Admission predictors of academic dismissal for provisional and traditionally admitted students. Curr Pharm Teach Learn. 2013;5(1):33-38. 10. Alston GL, Lane D, Wright NJD. The methodology for the early identification of students at risk for failure in a professional degree program. Curr Pharm Teach Learn. 2014;6(6):798-806.

11. American Association of Colleges of Pharmacy. Profile of Pharmacy Students Fall 2015. https://www.aacp.org/sites/default/ files/2017-10/Introduction.pdf. Accessed October 1, 2017. 12. Ambrose SA, Bridges MW, DiPietro M, Lovett MC, Norman MK, Mayer RE. How Learning Works. Seven Research-based Principles for Smart Teaching. San Francisco, CA: John Wiley and Sons Inc., 2010.

13. Bransford JD, Johnson MK. Contextual prerequisites for understanding: some investigations of comprehension and recall. $J$ Verbal Learn Verbal Behav.1972;11(6):717-726.

14. Brumby MN. Misconceptions about the concept of natural selection by medical biology students. Sci Educ. 1984;68(4):493-503. 


\section{American Journal of Pharmaceutical Education 2019; 83 (1) Article 6491.}

15. Hattie J, Timperley H. The power of feedback. Rev Educ Res. 2007;77(1):81-112.

16. Wehle S, Decker M. Perception of the relevance of organic chemistry in a German pharmacy students' course. Am J Pharm Educ. 2016;80(3):Article 40.

17. Chi MTH, Bassock M, Lewis MW, Reimann P, Glaser R. Selfexplanations: how students study and use examples in learning to solve problems. Cogn Sci. 1989;13(2):145-182.

18. Mar E, Barnett MJ, Tang TTL, Sasaki-Hill D, Kuperberg JR, Knapp K. Impact of previous pharmacy work experience on

pharmacy school academic performance. Am J Pharm Educ. 2010; 74(3):Article 42
19. Meagher DG, Pan T, Perez CD. Predicting performance in the firstyear of pharmacy school. Am J Pharm Educ. 2011;75(5):Article 81. 20. Schauner S, Hardinger KL, Graham MR, Garavalia L. Admission variables predictive of academic struggle in a PharmD program. Am J Pharm Educ. 2013;77(1):Article 8.

21. Cowart K, Dell K, Rodriguez-Snapp N, Petrelli HMW. An examination of correlations between MMI scores and pharmacy school GPA. Am J Pharm Educ 2016;80(6):Article 98. 22. Schlesselman LS, Coleman CI. Predictors of poor student performance at a single, Accreditation Council for Pharmacy Education-accredited school of pharmacy. Curr Pharm Teach Learn. 2011;3(2):101-105. 